\title{
Integrating the Transmission Loss Component with the Distribution Factors Enhanced Transmission Pricing Method for Efficient Transmission Use of System Charges
}

\author{
Nur Hanis Radzi ${ }^{a}$, Ramesh C. Bansal ${ }^{b^{*}}$, Zhao Yang Dong ${ }^{c} \&$ Mohammad Yusri Hassan $^{d}$ \\ a Department of Power Electrical Engineering, Universiti Tun Hussein Onn Malaysia (UTHM), Parit Raja, Johor, \\ Malaysia \\ ${ }^{\mathrm{b}}$ Department of Electrical, Electronic, and Computer Engineering, University of Pretoria, South Africa \\ ${ }^{\mathrm{c}}$ School of Electrical and Information Engineering, University of Sydney, New South Wales, Australia \\ ${ }^{\mathrm{d}}$ Department of Power Electrical Engineering, Universiti Teknologi Malaysia (UTM), Johor, Malaysia
}

\begin{abstract}
This article proposes a transmission pricing method that integrates the transmission loss component with the distribution factors enhanced transmission pricing method for the pool electricity market. Two new schemes are proposed: (1) New Scheme 1-the losses are allocated only for the locational charges and (2) New Scheme 2-the losses are allocated for both locational and non-locational charges. Both methods use justified distribution factors to evaluate the transmission line flows more accurately. The transmission losses are allocated among the market users by integrating the generalized generation justified distribution factors and generalized load justified distribution factors with the modified pro-rata method. The proposed approach is tested on the 10-machine IEEE 39-bus (New England) system to prove its effectiveness. Results show that the proposed method is able to reconcile transmission service cost fairly.
\end{abstract}

Keywords : distribution factors enhanced transmission pricing, justified distribution factors, locational and non-locational charges, loss allocation, pro-rata method, transmission pricing

\section{Introduction}

An important aspect in the restructured electricity market design is the transmission pricing method [1]. It is essential for a power market policy to satisfy all its users through a fair and equitable transmission charge scheme [2]. The following should be performed in transmission access pricing: charge the user for the actual utilization of the grid; provide signals to new power plants about best locations that can relieve transmission congestion and losses; be predictable, simple, and easy to implement and ensure recovery of total transmission revenue $[2,3]$. In the deregulation environment, one always disputable issue is allocating the power losses and dealing it with the transmission pricing. 
In the electricity trading arrangement operating under a pool power market, transmission cost allocation is a major issue, as it is difficult to detect the contribution of each user in a line since the power output from different power plants are "pooled" together to meet the required demand. With these issues, several strategies for transmission allocation have been proposed worldwide to provide an efficient economic signal to the transmission users as well as transmission utilities [4-10].

In recent years, distribution factors have been suggested as a popular mechanism to allocate transmission payments in restructured power systems, as these factors can efficiently evaluate transmission usage [10]. In addition, this is also because of its simplicity, linearity, and physical plausibility $[2,8]$. There are three approaches of distribution factors to allocate payments to different users of a transmission networks that are $A$ factors (to net injections), D factors (only to generators), and C factors (only to loads). However, these methods have some weaknesses since they rely on some conditions. For instance, the set of distribution factors for a pair of nodes found using a particular reference bus differs from the one using another bus [11]. This can cause consume more time to generate a new set of distribution factors if the users request to use different reference node to accommodate their transactions $[11,12]$. Furthermore, it would also be unsuitable to use it in transmission pricing or congestion management since the participants cannot predict the prices and avoid congestion of the network with ease if the reference is unknown [11]. To overcome this problem, a new technique has been successfully implemented independent of the references bus by making use of the properties of the distribution factors, called justified distribution factors (JDFs). JDFs are originally used to solve the congestion curtailment in the bilateral trading [11]. However, in [12], it was proved that JDFs can also be implemented in pool trading to estimate the contribution of the users in the line flows and at the same time to identify the counter-flow lines. The result generated from JDFs are used in generalized generation distribution factors (GGDFs) and generalized load distribution factors (GLDFs) to calculate the contribution of each market participant to the transmission line system in the PoolCo model.

Loss allocation is a procedure for subdividing the system transmission losses into fractions, the costs of which then become the responsibility of individual users of the power system (generation companies [GENCOs], distribution companies [DISCOs], marketers) [13]. The energy that flows into the meshed network to the loads needs to be traced, and the losses in the transmission networks need to be charged and transparently apportioned to the appropriate generator/load [14]. Unfortunately, it is not an easy task due to the non-linear characteristic of energy flow and losses in the networks. In this respect, a number of approximate models and algorithms have been introduced in the literature that try, as accurately as possible, to allocate the losses to the market users [14-24]. The developed loss allocation schemes can be categorized into incremental, circuit-based, proportionalsharing, pro-rata (PR), and miscellaneous approaches for bilateral transactions [13]. There are a number of new proposed methods that have been developed, such as the power flow based monetary flow method [3], the hybrid genetic algorithm-support vector machine technique [14], current adjustment factors (CAFs) [25], and bus impedance matrix ( $Z$ bus) based contribution factors [26], to improve the effectiveness of transmission loss allocation. However, they still have drawbacks while dealing with transmission pricing. First, these methods totally neglect counter-flows and always allocate positive losses. Counter- 
flows are very important to consider, as these can relieve the congested transmission lines. With regard to a fair transmission charging, a negative charge or credit can be given to the users that contribute counter-flows or negative losses. Second, the transmission usage and losses are calculated simultaneously. Therefore, the market operator cannot trace which market users contribute positive losses. This is very important for development of new power plant generation. New power plants should avoid being developed in areas that contribute more losses and congestions.

The cost of the basic transmission services corresponds primarily to the fixed transmission cost, also referred to as the embedded transmission facility cost [9]. The embedded cost is defined as the revenue requirements needed to pay for all existing facilities plus any new facilities added to the power system during the life of the contract for transmission service. The embedded cost methods are commonly used throughout the utility industry to allocate the cost of transmission services. The allocation of the embedded cost is done through usage calculation [27]. There are four different embedded costs of wheeling methods that could be used, namely the postage stamp method, contract path method, distance-based MW-mile method, and power flow based MW-mile method [28].

The MW-mile methodology may be regarded as the first pricing strategy proposed for the recovery of fixed transmission costs based on the actual use of transmission networks [9]. However, this method is not sufficient to cover the total transmission revenue. A new technique was introduced, namely the postage stamp coverage method, for the purpose of covering the total transmission system cost by sharing among the generators the costs associated with the unused capacity [29]. The method is simple, but its main drawback is that the charges paid by each user do not reflect the actual use that the users make of the network or the value they derive from being connected [2].

This article proposes novel transmission pricing approaches for allocating transmission service charges among pool market users. Generalized generation justified distribution factors (GGJDFs) and generalized load justified distribution factor (GLDFs) are used to trace the contribution of each generator/load to the network system accurately. The losses are allocated among the users by integrating the modified PR (MPR) method with the GGJDF and GLJDF approaches. This method has the ability to allocate system losses among different participants taking into account the counter-flows, which are detected by the GGJDFs and GLDFs. In addition, the user's location within the network is also considered by assigning losses according to the utilization of the grid. For transmission service charges, two schemes have been developed: (1) New Scheme 1 (NS1), which integrates the loss charge with conventional locational charges, and (2) New Scheme 2 (NS2), which integrates the loss charge with both conventional locational and non-locational charges. Both schemes are tested in a case study to identify which scheme is superior.

This article is organized as follows. Section 2 introduces a distribution factors enhanced transmission pricing (DFETP) method, and Section 3 presents the development of the MPR method to allocate losses among different uses. Section 4 describes the new transmission charge scheme formulation, and Section 5 provides a case study based on the 10-machine IEEE 39-bus (New England) system to show the merit of proposed scheme over the DFETP method. 


\section{DFETP Method}

The DFETP method proposed in $[30,31]$ is based on DC calculations and does not consider transmission losses. There are two subsections that follow for this approach: transmission usage evaluation and transmission pricing methods.

\subsection{Transmission Usage Evaluation}

JDFs were introduced in [11] to overcome the drawback of the distribution factors method in which it could cause more time to generate a new set of distribution factors if the users request to use a different reference node to accommodate their transactions [3]. JDFs are used to identify the net power flow in the transmission line system, where it is formed by adding a justification factor $J_{i j}$ to the original distribution factor, so that the distribution factors for line $i-j$ at bus $i$ and bus $j$ have the same magnitudes but opposite signs; this is written mathematically as [11]:

$$
\begin{aligned}
& J_{i j}^{m}=-\frac{D F_{i j}^{m}(i)+D F_{i j}^{m}(j)}{2}, \\
& J D F_{i j}^{m}=D F_{i j}^{m}+J_{i j}^{m}\{1\} .
\end{aligned}
$$

The power flow in line $i$ can be traced using Eq. (3):

$$
P_{i}=\sum_{j}^{m} J D F_{i}^{j} \cdot P_{j}
$$

where $J D F_{i}^{j}$ is the factor for line $i$ with respect to bus $j, P_{j}$ is the net injection power at bus $j$, and $m$ is the number of buses.

To calculate the circuit flow caused by each market user, GGJDFs and GLJDFs are used [12].

The GGJDF is mathematically written as

$$
J D_{i-j, g}=J D F_{i-j, g}+J D_{i-j},
$$

where $J D_{i-j}$ is calculated by

$$
J D_{i-j}=\frac{\left(F_{i-j}-\sum_{g} J D F_{i-j, g} \times G_{g}\right)}{\left(\sum_{g} G_{g}\right)},
$$

$J D$ factors $J D_{i-j, g}$ relates generation $G_{g}$ in a given bus $g$ with actual power flow $F_{i-j}$ in a line $i-j$ :

$$
F_{i-j}=\sum_{g} J D_{i-j, g} G_{g} .
$$


The GLDF is presented by the following equations:

$$
J C_{i-j, d}=J C_{i-j}-J D F_{i-j, d},
$$

where

$$
J C_{i-j}=\frac{\left(F_{i-j}+\sum_{d} J D F_{i-j, d} \times D_{d}\right)}{\left(\sum_{d} D d\right)} .
$$

The actual power flow $F_{i-j}$ in a line $i-j$ can be traced by relating the $J C$ factors with load $D_{d}$ in a given bus $d$ :

$$
F_{i-j}=\sum_{j} C_{i-j, d} D_{d}
$$

\subsection{Transmission Pricing Methods}

Transmission pricing methods are distinguished to two parts: (1) locational charges and (2) non-locational charges. The most common method for locational charges that has been implemented by utilities is the MW-mile method. The issue in this method concerns counterflow users, and it is still being debated as to what basis credit should be given to the transmission user who reduces the total net flow of the transmission system. However, many transmission utilities felt uncomfortable with the idea of providing a service and, in addition, paying the users for using it. The reason is clear, because giving credit to transmission users for their contribution in the counter-flow could cause difficulties for transmission utilities to recover the revenue requirements. Hence, the MW-mile method (negative-flow sharing) was introduced [28]. In this method, the negative value of $f k(u)$ is shared between the transmission owner and users using profit sharing factor $r$ [30]. This factor is determined according to the willingness of the transmission owner to share profit with the transmission users [32]. In this research, the profit-sharing factor is considered to be three, as there are three participants: the transmission owner, generator, and load. The charge levied to the user for using a set of circuit ks can be expressed mathematically as

$$
R(u)=\sum_{\text {allk }} C_{k} \frac{f_{k}(u)}{\overline{f_{k}}},
$$

where

$$
\begin{aligned}
& f_{k}(u)=+f_{k}(u)+\frac{1}{r}\left|-f_{k}(u)\right| ; \\
& \sum_{\text {allk }} C_{k} \text { is the total transmission revenue. }
\end{aligned}
$$


For non-locational charges, the postage stamp coverage method has been used by transmission utilities, for instance, the Electricity Supply Board National Grid (EirGrid, Republic Ireland) and Transend (Australia), to cover the total transmission revenue. This method can accurately cover the total revenue, but it seems unfair and inequitable if there is a local load case in the transmission network system. Therefore, a tracing-based postage stamp method was introduced in [31] where individual users are charged based on their actual usage of a transmission line system whether or not the network system consists of local load case.

For a generator, the power injected from $G_{i}$ to the transmission line, which is connected directly to bus $i$ where $G_{i}$ is located, is determined. Power from the generator at bus $i, G_{i}$, is injected to a transmission line system [33]:

$$
P_{G i T}=P_{i x}+P_{i y}+\ldots+P_{i n},
$$

where $P_{\text {in }}$ is the power flow in transmission line $n$, which is connected directly with bus $i$ where generator $G_{i}$ is located;

$$
\text { Remainder of } G_{i}\left(R G_{i}\right)=P_{G i}-P_{G i T}, P_{G i}>P_{G i T} \text {, }
$$

where $P_{G i}$ is the power output of generators of bus $i$;

$$
G_{i} \text { contributes to } D_{i}=R G_{i} \text {; }
$$

hence, the actual usage of $G_{i}$ in the transmission line system is $P_{G i T}$.

For load, the steps with the generator are similar to trace the power usage in the transmission line system. The load at bus $i, D_{i}$, received power from the transmission line system:

$$
P_{D i T}=P_{i x}+P_{i y}+\cdots+P_{i n},
$$

where $P_{\text {in }}$ is the power flow in transmission line $n$, which is connected directly with bus $i$ where load $D_{i}$ is located;

$$
\text { Remainder of } D_{i}\left(R D_{i}\right)=P_{D i}-P_{D i T}, P_{D i}>P_{D i T} \text {, }
$$

where $P_{D i}$ is the active power demanded by consumers of bus $i$;

$$
D_{i} \text { received power from } G_{i}=R D_{i} \text {; }
$$

therefore, the actual usage of $D_{i}$ in the transmission line system is $P_{D i T}$.

A new technique for the transmission pricing method is to charge market participants based on actual usage in the transmission line system. The actual power usage in the line system 
from Eqs. (12) and (17) will be used in the postage stamp coverage method to achieve a fair and equitable transmission service charge methodology [33].

The tracing-based postage stamp method can be described by Eqs. (18)-(21).

- For the generator:

$$
P S=\frac{\left(P_{c} \sum_{k=1}^{n l i n} C_{k}\right)-\sum_{i=1}^{n} R_{G i}}{\sum_{i=1}^{n} P_{G i T}}
$$

where $P_{c}$ is the percentage cost allocation of each network user, $R_{G i}$ is the allocated cost to generator $I$, and $C_{k}$ is the cost of circuit $k$.

- For the modified locational tariff for $G_{i}$ :

$$
\pi_{G i}=\frac{R_{G i}}{P_{G i T}} .
$$

- For load:

$$
P S=\frac{\left(P_{c} \sum_{k=1}^{n l i n} C_{k}\right)-\sum_{i=1}^{n} R_{D i}}{\sum_{i=1}^{n} P_{D i T}}
$$

where $R_{D i}$ is the allocated cost to demand $i$.

- For the modified locational tariff for $L_{i}$ :

$$
\pi_{L i}=\frac{R_{D i}}{P_{D i T}}
$$




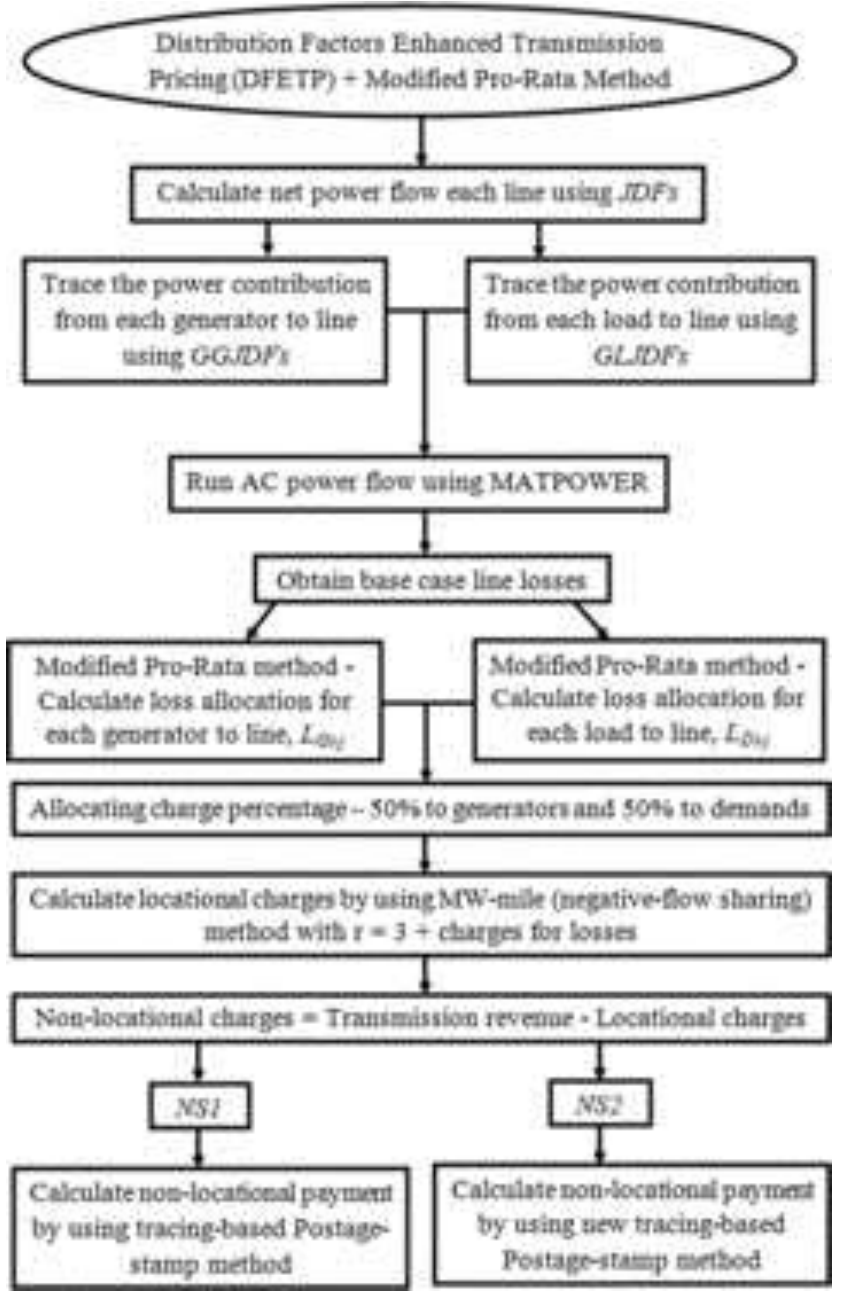

Figure 1 Proposed transmission pricing method.

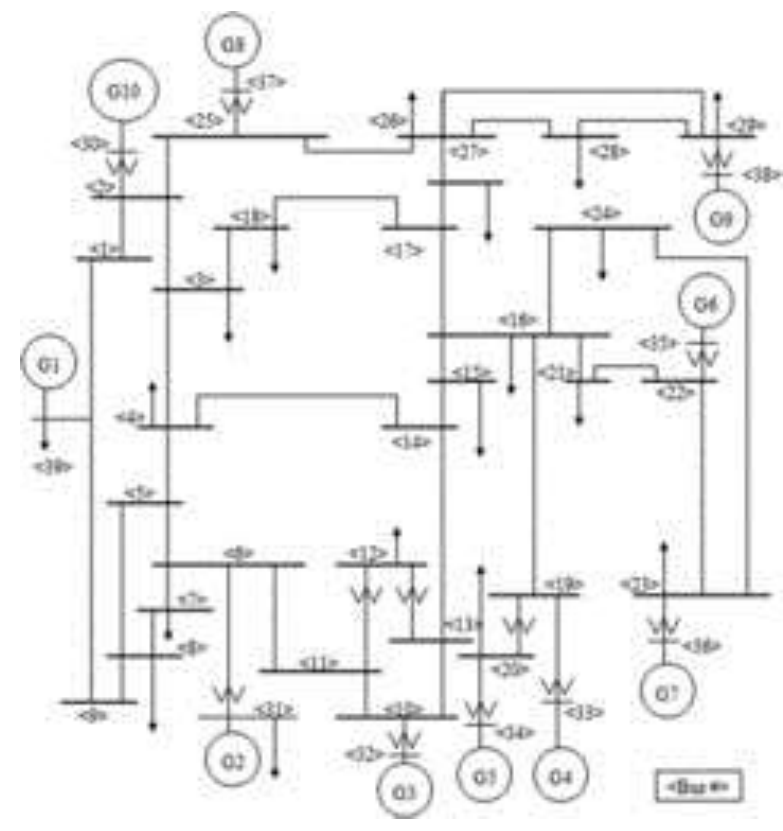

Figure 2 Ten-machine IEEE 39-bus (New England) system. 


\section{MPR Method}

The existing PR method proportionally allocates $50 \%$ of losses to loads and $50 \%$ to generators [15]; i.e.,

$$
L_{G i}=\frac{L}{2} \frac{P_{G i}}{P_{G}}, \quad L_{D j}=\frac{L}{2} \frac{P_{D j}}{P_{D}},
$$

where

$L_{G i}$ is the losses allocated to generator $i, L_{D j}$ is losses allocated to demand $j$, and $L$ denotes transmission power losses.

Generation and demand loss allocation factors are computed, respectively, as

$$
\begin{aligned}
L_{G i} & =\frac{L}{2} \frac{P_{G i}}{P_{G}}=K_{G} P_{G i}, & K_{G} & =\frac{1}{2} \frac{L}{P_{G}}, \\
L_{D j} & =\frac{L}{2} \frac{P_{D j}}{P_{D}}=K_{D} P_{D j}, & K_{D} & =\frac{1}{2} \frac{L}{P_{D}} .
\end{aligned}
$$

In this article, the MPR method is introduced by integrating the existing PR method with the GGJDF and GLJDF approaches to allocate the losses among different market users. The merit of this method is that it considers the counter-flows, which contribute negative losses.

Based on Eq. (22), let $P_{G i-j}$ and $P_{D i-j}$ denote the power contributed by generator $G$ and load $D$ to line $i-j$, which is determined by GGJDFs, and GLJDFs are used to replace $P_{G i}$ and $P_{D i} . P_{G i-j}$ and $P_{D i-j}$ can be $(+)$ or $(-)$ depending on the $J D$ and $J C$ factors. Thus, the equation implies that the line losses are distributed among participants based on the actual utilization of the line. In addition, for $P_{i-j}$, the net power flow in line $i-j$ is used instead of $P_{G}$ and $P_{D}$, as the analysis is based on the utilization of the transmission line system. Therefore, the contribution of losses of each market participant to the line system can be determined as

$$
\begin{aligned}
& L_{G i-j}=\frac{L_{i-j}}{2} \frac{P_{G i-j}}{P_{i-j}}, \quad L_{D i-j}=\frac{L_{i-j}}{2} \frac{P_{D i-j}}{P_{i-j}}, \\
& L_{G i-j}=\frac{L_{i-j}}{2} \frac{P_{G i-j}}{P_{i-j}}=K_{i-j} P_{G i-j}, \quad K_{i-j}=\frac{1}{2} \frac{L_{i-j}}{P_{i-j}}, \\
& L_{D i-j}=\frac{L_{i-j}}{2} \frac{P_{D i-j}}{P_{i-j}}=K_{i-j} P_{D i-j}, \quad K_{i-j}=\frac{1}{2} \frac{L_{i-j}}{P_{i-j}},
\end{aligned}
$$

where $L_{i-j}$ is the loss base case, which is determined from the AC power flow.

From Eqs. (25) and (26), it can be summarized that the loss contributed by each generator $G$ to line $i-j$ is

$$
L_{G i-j}=K_{i-j} P_{G i-j},
$$


Table 1 DC flow and loss base case

\begin{tabular}{|l|l|l|l|}
\hline Bus $i$ & Bus $j$ & DC flow base case, $P_{i j}(\mathrm{MW})$ & Loss base case, $L_{i j}(\mathrm{MW})$ \\
\hline
\end{tabular}

\begin{tabular}{|c|c|c|c|}
\hline 1 & 2 & -129.1 & 0.468 \\
\hline 1 & 39 & 129.1 & 0.369 \\
\hline 2 & 3 & 377.1 & 1.514 \\
\hline 2 & 25 & -256.2 & 3.804 \\
\hline 3 & 4 & 109.7 & 0.307 \\
\hline 3 & 18 & -54.5 & 0.039 \\
\hline 4 & 5 & -116.7 & 0.145 \\
\hline 4 & 14 & -273.6 & 0.556 \\
\hline 5 & 6 & -432.1 & 0.385 \\
\hline 5 & 8 & 315.4 & 0.78 \\
\hline 6 & 7 & 415.3 & 1.023 \\
\hline 6 & 11 & $\begin{array}{l}-379.5 \\
\end{array}$ & $\overline{c 0.867}$ \\
\hline 7 & 8 & 181.5 & 0.131 \\
\hline 8 & 9 & -25.1 & 0.133 \\
\hline 9 & 39 & -25.1 & 0.089 \\
\hline 10 & 11 & 378 & 0.499 \\
\hline 10 & 13 & 272 & 0.301 \\
\hline 13 & 14 & 263 & 0.657 \\
\hline 14 & 15 & -10.7 & 0.014 \\
\hline 15 & 16 & -330.7 & 0.935 \\
\hline 16 & 17 & 232.2 & 0.419 \\
\hline 16 & 19 & -512 & 3.645 \\
\hline 16 & 21 & -334.8 & 0.804 \\
\hline 16 & 24 & $\begin{array}{l}-45.1 \\
\end{array}$ & 0.021 \\
\hline 17 & 18 & 212.5 & 0.278 \\
\hline 17 & 27 & 19.7 & 0.089 \\
\hline 21 & 22 & -608.8 & 2.612 \\
\hline 22 & 23 & 41.2 & 0.019 \\
\hline 23 & 24 & 353.7 & 2.451 \\
\hline 25 & 26 & 59.8 & 0.296 \\
\hline 26 & 27 & 261.3 & 0.932 \\
\hline 26 & 28 & -145.4 & 0.763 \\
\hline 26 & 29 & -195.1 & 1.903 \\
\hline 28 & 29 & -351.4 & 1.612 \\
\hline 12 & 11 & 1.5 & 0.025 \\
\hline 12 & 13 & -9 & 0.036 \\
\hline 6 & 31 & -467.9 & 0 \\
\hline 10 & 32 & -650 & 0 \\
\hline 19 & 33 & -632 & 2.816 \\
\hline 20 & 34 & -508 & 2.406 \\
\hline
\end{tabular}




\begin{tabular}{|l||c||c|c|}
\hline Bus $i$ & Bus $j$ & DC flow base case, $\boldsymbol{P}_{i j}(\mathbf{M W})$ & Loss base case, $\boldsymbol{L}_{\boldsymbol{i}}(\mathbf{M W})$ \\
\hline 22 & 35 & -650 & 0 \\
\hline 23 & 36 & -560 & 1.391 \\
\hline 25 & 37 & -540 & 1.726 \\
\hline 2 & 3 & -250 & 0 \\
\hline 29 & 38 & -830 & 5.426 \\
\hline 19 & 20 & 120 & 0.278 \\
\hline \multicolumn{2}{l||}{ Total loss } & & 42.964 \\
\hline
\end{tabular}

and the loss contributed by each load $D$ to line $i-j$ is

$L_{D i-j}=K_{i-j} P_{D i-j}$

where $K_{i-j}$ is the loss allocation factor for line $i-j$.

\section{New Transmission Charge Scheme}

Two schemes introduced in this article are NS1 and NS2. For NS1, the loss charge integrates with conventional locational charges, while for NS2, the loss charge is considered for both conventional locational and non-locational charges. In case study, both schemes are tested to identify which scheme is superior and reflects a fair and equitable transmission pricing method.

\subsection{NS1}

By integrating the loss charge component with a DFETP locational signal, a new generation/demand locational charge equation can be obtained as follows.

- New locational charges for generator:

$$
R_{G i}=P_{c} \sum_{\text {allk }} C_{k} \frac{f_{k G i}+L_{k G i}}{\overline{f_{k}}}
$$

where $f_{k G i}$ is the $k$-circuit flow caused by generator $i, \overline{f_{k}}$ is the $k$-circuit capacity, and $L_{k G i}$ denotes the $k$-circuit losses caused by generator $i$.

- Locational tariff for generator:

$$
\pi_{G i}=\frac{R_{G i}}{P_{G i T}}
$$

- For demand: 


$$
R_{D i}=P_{c} \sum_{\text {allk }} C_{k} \frac{f_{k D i}+L_{k D i}}{\overline{f_{k}}}
$$

where $f_{k D i}$ is the $k$-circuit flow caused by demand $i$, and $L_{k D i}$ is the $k$-circuit losses caused by demand $i$.

- Locational tariff for demand:

$$
\pi_{D i}=\frac{R_{G i}}{P_{D i T}}
$$

\begin{tabular}{|c|c|c|c|c|c|}
\hline \multirow[b]{2}{*}{ Bus $i$} & \multirow[b]{2}{*}{ Bus $j$} & \multicolumn{2}{|c|}{ Usage allocation (MW) } & \multicolumn{2}{|c|}{ Loss allocation (MW) } \\
\hline & & G2 & G4 & G2 & G4 \\
\hline 1 & 2 & 3.0057 & -64.5008 & -0.0054 & 0.1169 \\
\hline 1 & 39 & -3.0057 & 64.5008 & -0.0043 & 0.0922 \\
\hline 2 & 3 & -48.039 & -66.1122 & -0.0964 & -0.1327 \\
\hline 2 & 25 & 51.0448 & 1.6113 & -0.3789 & -0.012 \\
\hline 3 & 4 & -141.477 & 32.2131 & -0.1981 & 0.0451 \\
\hline 3 & 18 & 68.2459 & -131.703 & -0.0244 & 0.0471 \\
\hline 4 & 5 & -197.485 & 60.7272 & 0.1227 & -0.0377 \\
\hline 4 & 14 & 16.8908 & -80.3429 & -0.0172 & 0.0816 \\
\hline 5 & 6 & -250.087 & -5.095 & 0.1114 & 0.0023 \\
\hline 5 & 8 & 52.6016 & 65.8222 & 0.065 & 0.0814 \\
\hline 6 & 7 & 95.906 & 62.4592 & 0.1181 & 0.0769 \\
\hline 6 & 11 & 130.2955 & -68.4975 & -0.1488 & 0.0782 \\
\hline 7 & 8 & 77.6146 & 38.2241 & 0.028 & 0.0138 \\
\hline 8 & 9 & 89.3774 & 49.9371 & -0.237 & -0.1324 \\
\hline 9 & 39 & 89.3774 & 49.9371 & -0.1586 & -0.0886 \\
\hline 10 & 11 & -118.307 & 62.6894 & -0.0781 & 0.0414 \\
\hline 10 & 13 & 118.3073 & -62.6894 & 0.0655 & -0.0347 \\
\hline 13 & 14 & 129.7087 & -62.275 & 0.162 & -0.0865 \\
\hline 14 & 15 & 146.5995 & -149.618 & -0.0961 & 0.0981 \\
\hline 15 & 16 & 121.5642 & -182.788 & -0.1719 & 0.2584 \\
\hline 16 & 17 & -18.2499 & 263.9653 & -0.0165 & 0.2381 \\
\hline 16 & 19 & 49.1317 & -566.903 & -0.1749 & 2.0179 \\
\hline 16 & 21 & 29.7058 & 39.3586 & -0.0357 & -0.0473 \\
\hline 16 & 24 & 35.2372 & 46.6875 & 0.0082 & -0.0109 \\
\hline 17 & 18 & -55.8847 & 148.0808 & -0.0366 & 0.0969 \\
\hline 17 & 27 & 37.6348 & 115.8845 & 0.0849 & 0.2615 \\
\hline 21 & 22 & 8.2694 & 10.9565 & -0.0177 & -0.0235 \\
\hline 22 & 23 & 8.2694 & 10.9565 & 0.0019 & 0.0025 \\
\hline
\end{tabular}

Table 2 Usage allocation, loss allocation, and locational charges for $\mathbf{G} 2$ and $\mathbf{G 4}$ 


\begin{tabular}{|c|c|c|c|c|c|}
\hline \multirow[b]{2}{*}{ Bus $i$} & \multirow[b]{2}{*}{ Bus $j$} & \multicolumn{2}{|c|}{ Usage allocation (MW) } & \multicolumn{2}{|c|}{ Loss allocation (MW } \\
\hline & & \begin{tabular}{|l|}
$G 2$ \\
\end{tabular} & $G 4$ & $G 2$ & $G 4$ \\
\hline 23 & 24 & -11.0939 & -14.6988 & -0.0384 & -0.0509 \\
\hline 25 & 26 & 33.5201 & -21.608 & -0.083 & -0.0535 \\
\hline 26 & 27 & -15.6507 & -86.7567 & 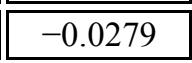 & -0.1547 \\
\hline 26 & 28 & 21.0949 & 27.9497 & $\begin{array}{c}-0.0554 \\
\end{array}$ & -0.0734 \\
\hline 26 & 29 & 17.2012 & 22.7907 & -0.0839 & -0.0151 \\
\hline 28 & 29 & 4.9785 & 6.5962 & 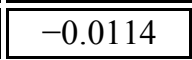 & 0.0486 \\
\hline 12 & 11 & -11.9881 & 5.8082 & -0.1003 & 0.0132 \\
\hline 12 & 13 & 11.4014 & -6.5856 & -0.0228 & 0 \\
\hline 6 & 31 & -476.288 & 0.9433 & 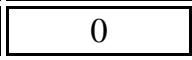 & 0 \\
\hline 10 & 32 & 0 & 0 & 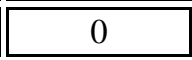 & 1.408 \\
\hline 19 & 33 & 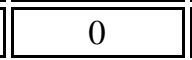 & -632 & 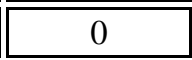 & 0 \\
\hline 20 & 34 & 0 & 0 & 0 & 0 \\
\hline 22 & 35 & 0 & 0 & 0 & 0 \\
\hline 23 & 36 & 0 & 0 & 0 & 0 \\
\hline 25 & 37 & 0 & 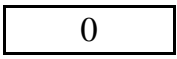 & 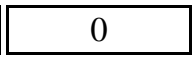 & 0 \\
\hline 2 & 3 & 0 & 0 & 0 & 0 \\
\hline 29 & 38 & 0 & 0 & 0 & 0 \\
\hline 19 & 20 & 49.1317 & 65.0969 & 0.0569 & 0.0754 \\
\hline Total allocated loss & -1.347 & +4.131 & & & \\
\hline DFETP $(\$)$ & $323,019.75$ & $330,327.63$ & - & - & \\
\hline Loss charges $(\$)$ & \begin{tabular}{|l|}
- \\
\end{tabular} & - & -223.47 & $\begin{array}{c}+686.05 \\
\end{array}$ & \\
\hline NS1 (\$) & - & - & $322,796.28$ & $331,013.68$ & \\
\hline NS2 (\$) & - & - & $322,796.28$ & \begin{tabular}{|l|}
$331,013.68$ \\
\end{tabular} & \\
\hline
\end{tabular}

Table 3 Locational charges for demands

\begin{tabular}{|c|c|c|c|c|}
\hline & \multicolumn{4}{|c|}{ Locational charges (\$) } \\
\hline \multicolumn{5}{|c|}{ Demand } \\
\hline at bus $i$ & DFETP & Loss charges & NS1 & NS2 \\
\hline$D 3$ & $138,862.07$ & 290.47 & $137,567.49$ & $137,567.49$ \\
\hline$D 4$ & $212,117.53$ & 576.07 & $212,693.6$ & $212,693.6$ \\
\hline$D 7$ & $155,255.68$ & 299.2 & $155,554.88$ & $155,554.88$ \\
\hline$D 8$ & $350,408.56$ & 704.91 & $351,113.47$ & $351,113.47$ \\
\hline$D 12$ & 4338.07 & 1.96 & 4340.03 & 4340.03 \\
\hline$D 15$ & $148,498.78$ & 234.09 & $148,728.87$ & $148,728.87$ \\
\hline$D 16$ & $146,145.96$ & 151.64 & $146,297.6$ & $146,297.6$ \\
\hline$D 18$ & $84,090.95$ & 117.78 & $84,208.73$ & $84,208.73$ \\
\hline$D 20$ & $449,992.74$ & 38.98 & $450,031.72$ & $450,031.72$ \\
\hline$D 21$ & $158,122.09$ & 67.06 & $158,189.15$ & $158,189.15$ \\
\hline$D 23$ & $178,341.74$ & -25.38 & $178,316.36$ & $178,316.36$ \\
\hline$D 24$ & $183,358.83$ & 132.56 & $183,491.39$ & $183,491.39$ \\
\hline
\end{tabular}




\begin{tabular}{|l||c|c|c|c||}
\hline \hline & \multicolumn{4}{|c|}{ Locational charges (\$) } \\
\hline Demand & \multicolumn{3}{|c|}{} \\
\hline \hline at bus $\boldsymbol{i}$ & DFETP & Loss charges & NS1 & NS2 \\
\hline$D 25$ & $109,700.52$ & -105.43 & $109,595.09$ & $109,595.09$ \\
\hline$D 26$ & $72,432.37$ & 41.67 & $72,474.04$ & $72,474.04$ \\
\hline$D 27$ & $159,890.61$ & 213.38 & $160,103.99$ & $160,103.99$ \\
\hline$D 28$ & $139,671.96$ & -27.52 & $139,644.44$ & $139,644.44$ \\
\hline$D 29$ & $205,543.62$ & -145.63 & $205,397.99$ & $205,397.99$ \\
\hline$D 31$ & 6652.21 & 9.58 & 6661.79 & 6661.79 \\
\hline$D 39$ & $720,481.18$ & 992.57 & $721,473.75$ & $721,473.75$ \\
\hline Total & $3,623,901.47$ & 3567.96 & $3,627,469.42$ & $3,627,469.42$ \\
\hline
\end{tabular}

The non-locational charges for both users are recovered by using the tracing-based postage stamp method as shown in Eqs. (18)-(21).

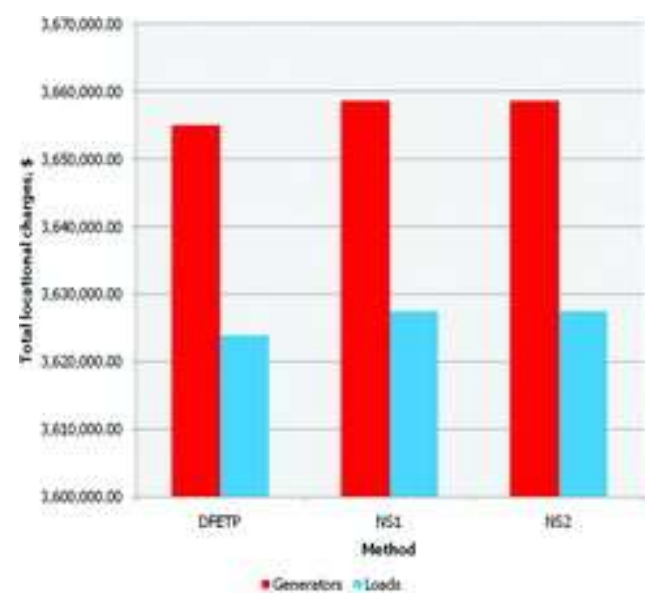

Figure 3 Total locational charges for generators and loads.

Table 4 Non-locational charges for G2 and G4

\begin{tabular}{|c|c|c|c|c|c|c|}
\hline & \multicolumn{3}{|c|}{ Node 31} & \multicolumn{3}{|c|}{ Node 33} \\
\hline A. Generation (MW) & 476.29 & & & 632 & & \\
\hline B. Losses (MW) & & -1.347 & & & +4.131 & \\
\hline $\mathrm{A}+\mathrm{B}(\mathrm{MW})$ & & & 474.943 & & & 636.131 \\
\hline DFETP (\$) & $197,842.68$ & & & $262,521.93$ & & \\
\hline NS1 (\$) & $197,555.39$ & & & $262,140.72$ & & \\
\hline NS2 (\$) & $196,840.60$ & -556.85 & $196,283.75$ & $261,192.25$ & +1707.09 & $262,899.34$ \\
\hline
\end{tabular}

\subsection{NS2}

By integrating the loss charge component with DFETP locational and non-locational signal, a new generation/demand locational charge equation can be obtained as follows:

- New locational charges for generator: 


$$
R_{G i}=P_{c} \sum_{\text {allk }} C_{k} \frac{f_{k G i}+L_{k G i}}{\overline{f_{k}}} .
$$

- Locational tariff for generator:

$$
\pi_{G i}=\frac{R_{G i}}{P_{G i T}+T L_{G i}}
$$

where $T L_{G i}$ denotes total losses contributed from $G i$.

- For demand:

$$
R_{D i}=P_{c} \sum_{\text {allk }} C_{k} \frac{f_{k D i}+L_{k D i}}{\overline{f_{k}}}
$$

- Locational tariff for demand:

$$
\pi_{D i}=\frac{R_{D i}}{P_{D i T}+T L_{D i}},
$$

where $T L_{D i}$ denotes total losses contributed from $D i$.

Finally, the transmission cost not remunerated is recovered by using the new tracing-based postage stamp method.

- Non-locational tariff for generator:

$$
\pi P S_{G i}=\frac{\left(P_{c} \sum_{k=1}^{n l i n} C_{k}\right)-\sum_{i=1}^{n} R_{G i}}{\sum_{i=1}^{n} P_{G i T}+T L_{G i}} .
$$

- Non-locational charges for each generator:

$$
P S_{G i}=\pi P S_{G i} \times\left(P_{G i T}+T L_{G i}\right) \text {. }
$$

- Non-locational tariff for demand:

$$
\pi P S_{D i}=\frac{\left(P_{c} \sum_{k=1}^{n l i n} C_{k}\right)-\sum_{i=1}^{n} R_{D i}}{\sum_{i=1}^{n} P_{D i T}+T L_{D i}} .
$$


- Non-locational charges for each demand:

$$
P S_{G i}=\pi P S_{G i} \times\left(P_{D i T}+T L_{D i}\right) .
$$

The proposed approach can be summarized by the flowchart shown in Figure 1 .

\section{Case Study}

The IEEE 39-bus test system shown in Figure 2 is selected using the proposed method. The parameters for the system were reported in $[34,35]$. The capacity of all circuits is assumed to be $800 \mathrm{MW}$. The system consists of 10 generators producing a total power of 6139.964 MW and 19 loads that need a total of $6097 \mathrm{MW}$. There is local load at buses 31 and 39. Let the total transmission revenue be $\$ 12,224,200$.

Table 5 Non-locational charges for D29 and D39

\begin{tabular}{|c|c|c|c|c|c|c|}
\hline & \multicolumn{3}{|c|}{ Node 29} & \multicolumn{3}{|c|}{$\begin{array}{l}\text { Node } 39 \\
\end{array}$} \\
\hline A. Generation (MW) & 283.5 & & & 922.93 & & \\
\hline B. Losses (MW) & & -0.877 & & & +5.973 & \\
\hline $\mathrm{A}+\mathrm{B}(\mathrm{MW})$ & & & 282.623 & & & 928.903 \\
\hline DFETP (\$) & $119,252.42$ & & & $388,224.46$ & & \\
\hline NS1 (\$) & $119,081.42$ & & & $387,667.76$ & & \\
\hline NS2 (\$) & $118,650.56$ & \begin{tabular}{|l|}
-367.00 \\
\end{tabular} & $118,283.56$ & $386,265.11$ & +2499.99 & $388,765.10$ \\
\hline
\end{tabular}

Table 1 shows the DC flow base case using the JDFs method and the loss base case obtained from MATPOWER analysis.

Table 2 shows the usage allocation, loss allocation, and locational charges for $G 2$ at node 31 and $G 4$ at node 33. The usage allocation is obtained by using the GGJDF method, while for loss allocation, MPR methods are adopted. As can be seen, the total loss allocated for $G 2$ and $G 4$ are -1.347 and +4.131 , respectively. Hence, by applying the proposed method, $G 2$ will pay less as it contributes negative losses. On the other hand, high charges for $G 4$ contributes positively to system losses, and this makes the payment higher after integrating the loss component. The locational charges for NS1 and NS2 are similar as both methods considered losses in transmission charging.

Table 6 Non-locational tariff for market users

\begin{tabular}{|l||c|c|c|}
\hline & \multicolumn{2}{|c|}{ Non-locational tariff (\$/kW) } \\
\hline \hline Users & DFETP & NS1 & NS2 \\
\hline \hline Generators & 0.4154 & 0.4148 & 0.4133 \\
\hline Loads & 0.4206 & 0.4200 & 0.4185 \\
\hline
\end{tabular}

Table 3 shows the locational charges by using DFETP and the proposed methods, which are NS1 and NS2 for demands. It clearly shows that positive losses increase the locational charges, while incentives are given to the demand, which contributes negative losses. As the 
total loss charge is $\$ 3567.96$, the total locational charge is increased from $\$ 3,623,901.47$ to $\$ 3,627,469.42$. As shown in Figure 3, with the presence of losses charges, total locational charges for generators and demands are increased.

Table 4 shows the non-locational charges for the generator at nodes 31 and 33 . The generation for $G 2$ is actually $477 \mathrm{MW}$, but due to the local load, $G 2$ only uses $476.290 \mathrm{MW}$ in the transmission line system. The actual power usage of the generator in transmission line system $P_{G i T}$ can be determined by using the tracing-based postage stamp method. The non-locational charges for NS1 and NS2 are lower than the DFETP method because the locational charges for both proposed methods are high compared to the DFETP method. The loss charges are taken into account in the NS2 method. Hence, it can be seen in Table 4 that $G 2$ paid less non-locational charges, as a negative charge is allocated to it. A similar result is also shown for demand in Table 5, where for $D 29, \$ 367$ is credited from the total nonlocational charge, which decreases from $\$ 118,650.56$ to $\$ 118,283.56$ as $D 29$ contributes negative losses.

Figure 4 compares the total non-locational charges for the DFETP, NS1, and NS2 methods. The total non-locational charges are less for the proposed scheme, and this is significant as for the locational charges; the proposed scheme takes into consideration both the user's utilization in the network and the loss contributed by that user within the line.

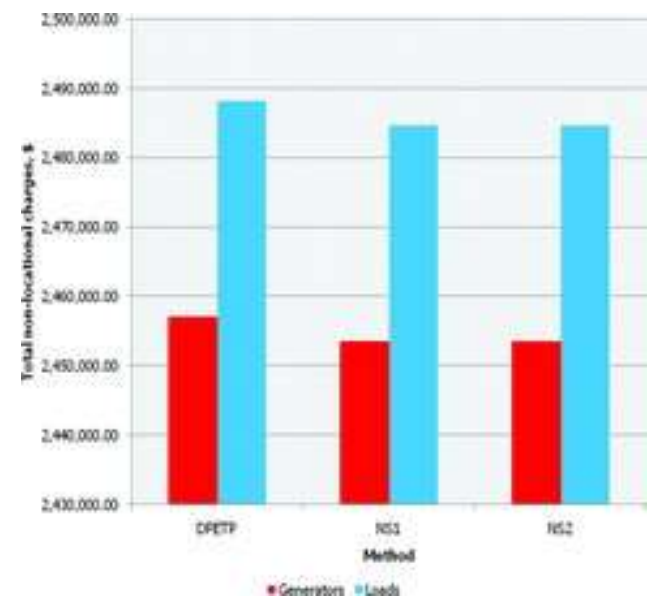

Figure 4 Total non-locational charges for generators and loads.

As can be observed from Table 6 and Figure 5, the proposed NS1 and NS2 allocate less nonlocational tariff because the locational charges for both methods consider the losses. The losses are taken into consideration in non-locational charges by NS2. Hence, the nonlocational tariff for NS2 is less than that for NS1. Incentives are given to the user for loss reduction. On the other hand, they will be charged more if they contributes more losses to the network system. 


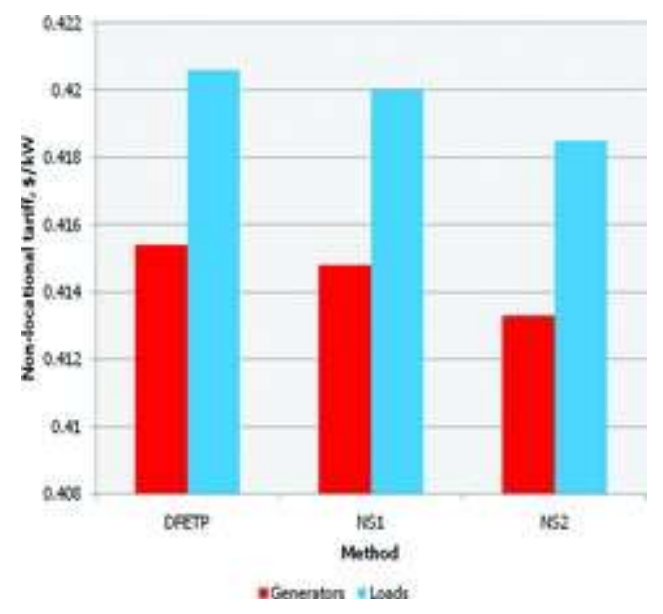

Figure 5 Non locational tariff for market users using existing and proposed schemes.

\section{Conclusion}

This article has proposed two new schemes-NS1 and NS2 - for transmission service charges in pool power markets. For both methods, JDFs, GGJDFs and GLJDFs are used for transmission usage allocation among different transmission users. Losses are considered in the locational charges for both schemes. The losses are allocated for different market users by using the MPR method, which integrates GGJDFs and GLJDFs with the existing PR method. This method has the ability to allocate system losses among different network users in each line, taking into account the counter-flow detected by GGJDFs and GLDFs. Thus, the merit of the proposed methods lies on rewarding the user for relieving the transmission losses, and this yields less locational charges paid by that user. For nonlocational charges, only NS2 considered losses in transmission charging. The market users are charged based on their actual usage and loss contribution in each transmission line system. Incentives are given to the users that relieve the transmission system losses. In addition, the advantage of this proposed scheme is to encourage new power plants to be built in appropriate locations for relieving the transmission load. In conclusion, NS2 is superior to other methods, as it reflects fair and equitable transmission service charges. In this scheme, both locational and non-locational charges are assigned to the market users based on their usage and loss contributed in the transmission line.

\section{Funding}

Author Radzi wishes to acknowledge University Tun Hussein Onn Malaysia for its financial support.

\section{References}

1. Bhakar, R., Sriram, V.S., Padhy, N.P., and Gupta, H.O., "Transmission embedded cost allocation in restructured environment: A game-theoretic approach," Elect. Power Compon. Syst., Vol. 37, No. 9, pp. 970-981, March 2009. 
2. Hassan, M.Y., Almaktar, M.A., Abdullah, M.P., Hussin, F., Majid, M.S., and Rahman, H.A., "The impact of transmission loss component on transmission cost recovery in pool electricity markets," Int. Rev. Elect. Eng., Vol. 5, No. 4, pp. 1736-1746, August 2010.

3. Duan, G., Dong, Z.Y., Bai, W., and Wang, X.F., "Power flow based monetary flow method for electricity transmission and wheeling price," Elect. Power Syst. Res., Vol. 74, No. 2, pp. 293-305, 2005.

4. Bialek, J., "Tracing the flow of electricity," Proc. IEE Generat. Transm. Distribut., Vol. 143, No. 4, pp. 313-320, 1996.

5. Kirschen, D., Allan, R., and Strbac, G., "Contributions of individual generators to loads and flows," IEEE Trans. Power Syst., Vol. 12, No. 1, pp. 52-60, 1997.

6. Kirschen, D., and Strbac, G., "Transmission networks and electricity markets," in Fundamentals of Power System Economics, Chichester, England: John Wiley \& Sons, Ltd, Chap. 6, pp. 141-200, 2004.

7. Galetovic, A., and Montecinos, C.M., "The new Chilean transmission charge scheme as compared with current allocation methods," IEEE Trans. Power Syst., Vol. 21, No. 1, pp. 99107, 2006.

8. Rudnick, H., Palma, R., and Fernandez, J.E., "Marginal pricing and supplement cost allocation in transmission open access," IEEE Trans. Power Syst., Vol. 10, No. 2, pp. 11251142, 1995.

9. Jiuping, P., Teklu, Y., Rahman, S., and Jun, K., "Review of usage-based transmission cost allocation methods under open access,"IEEE Trans. Power Syst., Vol. 15, No. 4, pp. 12181224, 2000.

10. Shahidehpour, M., Yamin, H., and Li, Z., "Transmission congestion management and pricing," in Market Operations in Electric Power Systems, New York: The Institute of Electrical and Electronics Engineers, Inc., Chap. 10, pp. 369-454, 2002.

11. Yuen, Y.S. C., and Lo, K.L., "Simulation of bilateral energy markets using Matlab," Int. J. Computat. Math. Elect. Electron. Eng., Vol. 22, No. 2, pp. 424-443, 2003.

12. Radzi, N.H., Dong, Z.Y., and Bansal, R.C., "Justified distribution factors approach for pool modelling," 9th International Power and Energy Conference (IPEC), pp. 1117-1122, Singapore, 27-29 October 2010.

13. Galiana, F.D., Canejo, A.J., and Kockar, I., "Incremental transmission loss allocation under pool dispatch," IEEE Trans. Power Syst., Vol. 17, No. 1, pp. 26-33, February 2002.

14. Mustafa, M.W., Sulaiman, M.H., Shareef, H., and Khalid, S.N. A., "Transmission loss allocation in deregulated power system using the hybrid genetic algorithm-support vector machine technique," Cyber J. Select. Areas Renew. Sustain. Energy, Vol. 2, No. 1, pp. 10-19, 2011. 
15. Fadiland, S., and Sarioglu, G.R., "An active and reactive power dispatch technique for a power system area using spot price of electricity," Elect. Machines Power Syst., Vol. 26, pp. 399-413, May 1998.

16. De, M., and Goswami, S.K., "A direct and simplified approach to power-flow tracing and loss allocation using graph theory," Elect. Power Compon. Syst., Vol. 38, No. 3, pp. 241-259, January 2010.

17. Wu, Z.Q., "Loss and branch power flow allocation based on topological method," Elect. Power Compon. Syst., Vol. 30, No. 11, pp. 1179-1193, May 2002.

18. Conejo, A.J., Arroyo, J.M., Alguacil, N., and Guijarro, A.L., "Transmission loss allocation: A comparison of different practical algorithms,"IEEE Trans. Power Syst., Vol. 17, No. 5, pp. 571-576, 2002.

19. Jing, D., Phulpin, Y., Rious, V., and Ernst, D., "How compatible is perfect competition with transmission loss allocation methods?" 5 th International Conference on European Electricity Market, pp. 1-6, Lisbon, Portugal, 28-30 May 2008.

20. Menezes, T.V., Da Silva, L.C. P., and Castro, M.S., "A comparative analysis of AC and DC incremental methods for transmission loss allocation," Elect. Power Compon. Syst., Vol. 34, No. 5, pp. 521-537, May 2006.

21. Ogawa, T., Kadota, S., and Iwamoto, S., "Transmission line loss allocation using power flow tracing with distribution factors," IEEE Power Engineering Society General Meeting, pp. 1-7, Tampa, FL, USA, 24-28 June 2007.

22. Sulaiman, M.H., Mustafa, M.W., and Aliman, O., "Power flow and loss tracing in deregulated transmission system using proportional tree method," Int. Rev. Elect. Eng., Vol. 3, No. 4, pp. 691-698, August 2008.

23. Teng, J.H., "Power flow and loss allocation for deregulated transmission systems," Int. J. Elect. Power Energy Syst., Vol. 27, No. 4, pp. 327-333, 2005.

24. Dehaghan, H.S., Abyaneh, H.A., and Javidi Dasht-Bayz, M.H., "Transmission expansion planning and cost allocation under market environments," Elect. Power Compon. Syst., Vol. 6, No. 2, pp. 156-165, March 2011.

25. Alturki, Y.A., and Lo, K.L., "Real and reactive power loss allocation in pool-based electricity markets," Int. J. Elect. Power Energy Syst., Vol. 32, No.4, pp. 262-270, 2010.

26. Singh, K., Yadav, V.K., Padhy, N.P., and Sharma, J., "Congestion management considering optimal placement of distributed generator in deregulated power system networks," Elect. Power Compon. Syst., Vol. 42, No. 1, pp. 13-22, December 2013.

27. Kovacs, R.R., and Leverett, A.L., "A load flow based method for calculating embedded, incremental and marginal cost of transmission capacity,"IEEE Trans. Power Syst., Vol. 9, No. 1, pp. 272-278, 1994. 
28. Lo, K.L., Hassan, M.Y., and Jovanovic, S.A., "Assessment of MW-mile method for pricing transmission services: A negative flow-sharing approach," IET Proc. Generat. Transm. Distribut., Vol. 1, No. 6, pp. 904-911, 2007.

29. EIRGRID, “Explanatory paper for 2007/2008 statement of charges," pp. 1-31, 2008, available at: www.eirgrid.com

30. Radzi, N.H., Dong, Z.Y., and Hassan, M.Y., "A new transmission charging methodology for Australian national electricity market," IEEE PES Innovative Smart Grid Technologies Asia (ISGT), pp. 1-8, Perth, 13-16 November 2011.

31. Radzi, N.H. M., Bansal, R.C., Dong, Z.Y., Hassan, M.Y., and Wong, K.P., "An efficient distribution factors enhanced transmission pricing method for Australian NEM transmission charging scheme," Renew. Energy, Vol. 53, pp. 319-328, 2013.

32. Hassan, M.Y., Majid, M.S., Hussin, F., Rahman, H.A., and Lo, K.L., "Certain considerations in pricing unbundled transmission services," Proceedings of the Power Engineering Conference, pp. 272-275, Putrajaya, Malaysia, 28-29 November 2006.

33. Radzi, N.H., Bansal, R.C., Dong, Z.Y., and Hassan, M.Y., "Modification $n$ postage-stamp coverage method for local load case of transmission service charges," 4th International Conference on Electric Utility Deregulation and Restructuring and Power Technologies (DRPT), Weihai, Shandong, China, 6-9 July 2011, available at: http://www.drpt2011.org/.

34. "IEEE 10 generator 39 bus system," available at: http://sys.elec.kitamiit.ac.jp/ueda/demo/WebPF/39-New-England.pdf

35. Bhattacharjee, T., and Chakraborty, A.K., "NSGAll-based congestion management in a pool-based electricity market incorporating voltage and transient stability," Elect. Power Compon. Syst., Vol. 41, No. 10, pp. 990-1001, June 2013. 